\title{
CLONACIÓN HUMANA REPRODUCTIVA, TERAPÉUTICA Y SOCIAL
}

\section{Reproductive, therapeutic and social human cloning}

\author{
José Maria Cantú \\ Centro Universitario de Ciencias de la Salud de la Universidad Nacional Autónoma \\ de México, México - D. F., México. \\ chema@cencar.udg.mx
}

\author{
Diana Resendez Pérez \\ Facultad de Ciencias Biológicas de la Universidad Autónoma de Nuevo León, \\ Monterrey, México. \\ dresende@ccr.dsi.uanl.mx
}

\author{
Ute Schmidt Osmanczik \\ Instituto de Investigaciones Filológicas de la Universidad Nacional Autónoma de \\ México, México D. F., México. \\ osmanczi@servidor.unam.mx
}

\begin{abstract}
Resumen: El término clonación ha tenido diversos usos y significaciones. Después de describir los procesos de desarrollo y diferenciación celular y los primeros experimentos, pasamos al problema de la clonación humana propiamente dicha. Ésta, puede realizarse teniendo en vista dos finalidades: la reproductiva y la terapéutica. Sobre éstas, discutimos tanto las circunstancias que las justifican como las objeciones éticas, legales y sociales a estas prácticas. Discutimos también el impacto de la clonación en la fabricación de productos biofarmacéuticos, sus limitaciones y ventajas. Al fin, trazamos consideraciones éticas y sociales relacionadas al tema, sus perspectivas y límites éticos, denunciando la clonación social que se verifica en la reproducción del "paupericidio" y en la peligrosa homogenización propiciada por la masiva tecnología de la comunicación que pretende enseñarnos a vivir con lo inaceptable.
\end{abstract}

Palabras-clave: Clonación humana. Clonación con fines reproductivos. Clonación con fines terapéuticos. Clonación social. Bioética. Derechos Humanos.

\begin{abstract}
The term "cloning" has been used in many different ways. That can be undertaken for reproductive or therapeutic purposes. We present the circumstances that would justify those kinds of cloning as well as medical, legal and social objections related to these practices. We also discuss the impact of cloning in the manufacturing of biopharmaceutical products, including its limitations and advantages. At last, the article makes ethical and social considerations about this topic, its perspectives and ethical limits. The study denounces the social cloning that can be found in the reproduction of the genocide of the poor ("poorcide") and also the dangerous homogenization made possible by the massive communication technology which intends to teach us how to live with the unacceptable.
\end{abstract}

Key words: Human cloning. Reproductive cloning. Therapeutic cloning. Social cloning. Bioethics. Human Rights. 
E l término clonación procede del griego klon, que significa retoño, rama o brote. Inicialmente, fue utilizado para designar a un conjunto de plantas generado por multiplicación vegetativa, de manera que la población así obtenida conserva la información genética presente en la planta que le dio origen. Posteriormente, el concepto de clon se aplicó, por extensión, a poblaciones de células y organismos obtenidos mediante reproducción asexual. La palabra clonación también se ha utilizado para definir al procedimiento que lleva a la obtención de copias de moléculas de ADN (ácido desoxirribonucleico). En el presente trabajo, nos enfocamos a la clonación que implica la generación de uno o varios organismos a partir del núcleo de una célula somática obtenida de un donador, de forma que los organismos clonados son idénticos o casi idénticos al genoma original. En este proceso, se transfiere el núcleo proveniente de una célula somática de un donador a un óvulo al que previamente se le eliminó el núcleo (enucleación), para luego ser implantado en el útero de una hembra preparada para la gestación. El producto es casi idéntico al individuo donante. La diferencia podría deberse al genoma citoplásmico (mitocondrial) procedente del óvulo receptor y/o a las mutaciones somáticas producidas en la célula donante.

La reproducción asexual constituye, en sí misma, una forma de clonación. En aquellos organismos que son capaces de reproducirse a partir de la división de una célula de un sólo individuo, la población generada compartirá información genética idéntica, a menos que ésta sea modificada por algún evento de mutación espontánea. Por otra parte, también es posible, aunque sea de rara frecuencia, la producción de clones de organismos superiores mediante reproducción asexual, como es el caso de la partenogénesis ("originado por una virgen").

En animales superiores, la única forma de reproducción es la sexual: en la que se unen dos células germinales o gametos (óvulo y espermatozoide), provenientes de cada uno de los padres, formando un huevo, o cigoto, que se desarrollará hasta constituir al organismo adulto. Este nuevo organismo contendrá el genoma proveniente de ambos gametos, es decir, una combinación de genes nueva y única. La reproducción sexual es el "invento" evolutivo que garantiza que, en cada generación, existan nuevas combinaciones de genes para incrementar la variabilidad genética de los diferentes organismos, necesaria en los procesos de la selección natural y la evolución. 


\section{Desarrollo y Diferenciación Celular}

El desarrollo del embrión se inicia con la fertilización del óvulo por el espermatozoide, dando origen al cigoto o protoembrión unicelular. Éste sufre una serie de divisiones celulares, generándose células denominadas blastómeros. En las primeras divisiones, cada una de las células es totipotente, es decir, en forma individual, tienen la capacidad de dar lugar a un organismo completo. Estas primeras células del embrión son conocidas como células madre (también llamadas troncales, tallo, estaminales, seminales: son totipotenciales que pueden diferenciarse a cualquier tipo de célula somática.

Después de cuatro divisiones celulares, y hasta la novena, las células madre pierden la capacidad de formar un organismo, pero pueden diferenciarse en cualquier tipo de célula, excepto placenta. Se les llama, ahora, pluripotenciales. Posteriormente, se forma el blastocisto, y de ahí en adelante las células madre pierden versatilidad, ya que reducen el número de tipos de célula en los que pueden diferenciarse. Se les conoce, ahora, como multipotenciales. Después de eso, se crea una capa externa, que genera el trofoblasto para dar origen a la placenta y a la masa celular interna, que formará las tres capas de tejido embrionario - el endodermo, el mesodermo y el ectodermo - de dónde se formarán todos los tejidos del embrión.

El desarrollo de un organismo es el proceso en que cada una de las células se especializa para desarrollar las funciones del tejido u órgano específico que van a integrar. La diferenciación celular es un mecanismo altamente complejo, que se lleva a cabo mediante la activación y represión de un gran número de genes en una forma muy precisa en espacio y tiempo, que está "secuencialmente programada" en respuesta a estímulos extracelulares y intracelulares. Las células somáticas, que constituyen los tejidos de un animal adulto, son el producto de la división y diferenciación del cigoto que, a diferencia de las células madre, han perdido la totipotencia y se han diferenciado para realizar una función específica, aunque mantienen el mismo material genético y no presentan alteraciones en la organización del genoma.

\section{Primeros Experimentos de Clonación}

El primer experimento de clonación en vertebrados fue realizado en 1952 (BRIGGS \& KING, 1952) usando ovocitos de rana pues, por ser células 
grandes, ellas facilitan la manipulación necesaria para la eliminación del núcleo. En este experimento, fue posible micro-inyectar núcleos indiferenciados de un organismo donador a huevos fertilizados previamente enucleados. La progenie resultante contenía la información genética del donador, por lo que los organismos constituyeron una clona genética del mismo. Posteriormente, Gurdon logró colecciones idénticas de Xenopus laevis al introducir núcleos de células de fases larvarias tempranas en ovocitos enucleados (GURDON, 1962). Este experimento funcionó únicamente con núcleos obtenidos de células en fases larvarias. No se tuvo éxito cuando se utilizaron núcleos de células donadoras adultas ya diferenciadas (GURDON et. al., 1975). Estos resultados mostraron que el núcleo de las células diferenciadas no fue capaz de activar el proceso de diferenciación del ovocito tal y como se había observado en los experimentos previos con el núcleo de las células embrionarias.

Ante la interrogante sobre ¿̇si era posible la clonación en organismos superiores? diferentes grupos de investigación llegaron a la siguiente conclusión: no era posible reiniciar el desarrollo de un organismo completo a partir del núcleo de una célula diferenciada (MCGRATH et al., 1984). Esta conclusión, que ahora sabemos era errónea, se consideró cierta durante mucho tiempo, estableciendo que el genoma de una célula especializada estaba restringido exclusivamente a las funciones de la célula diferenciada.

\section{Clonación de Mamíferos a Partir de Una Célula Diferenciada}

El procedimiento de clonación dejó de ser una fantasía, convirtiéndose en realidad, cuando la mundialmente famosa oveja Dolly fue clonada a partir del núcleo de una célula diferenciada. En este experimento fue utilizada una célula de glándula mamaria de una oveja adulta de la raza Finn Dorset como donadora del núcleo (WILMUT et al., 1997) Éste fue transferido a un óvulo enucleado de otra oveja e implantado en una hembra de la raza Scottis Blackfase para la gestación. En este experimento, de los 277 ovocitos enucleados, se lograron obtener sólo 29 blastocitos fenotípicamente normales después de seis días de cultivo in vitro. Cuando los embriones fueron transferidos a hembras receptoras preparadas hormonalmente, resultó un sólo producto viable: la oveja Dolly. Los restantes fueron fetos y neonatos muertos, o productos con alteraciones en el desarrollo. Esta baja eficiencia para obtener productos viables explica el fracaso de los primeros experimentos de este tipo. 
La producción del primer mamífero clonado a partir del núcleo de una célula diferenciada mostró que es posible "reprogramar" el genoma de una célula diferenciada por influencia del citoplasma del huevo, reiniciando el complejo proceso de desarrollo embrionario.

Por otro lado, este avance científico permitió la clonación en otras especies, aunque los individuos no siempre fueron obtenidos de núcleos de células somáticas del organismo adulto. Como ejemplos de eso, podemos mencionar el cordero Polly, conteniendo genes humanos (COLMAN, 1999); la producción exitosa de los monos Rhesus Neti y Ditto, mediante transferencia nuclear de células embrionarias; la clonación del gato doméstico CC (del inglés Copy Cat - copia al carbón); diferentes ratones (HOSAKA et al., 2000) e incluso cerdos (POLEJAEVE et al., 2000).

\section{Transferencia Nuclear de Células Somáticas}

Los estudios iniciales en la transferencia nuclear en anfibios y mamíferos fallaron, en la mayoría de los casos, debido a la incompatibilidad entre los ciclos celulares del núcleo donante y el ovocito receptor. El núcleo en fase $\mathrm{S}$ o G2 se introducía en un ovocito detenido en metafase II, produciendo una replicación adicional del ADN y una condensación prematura de los cromosomas, dando como resultado aneuploidías y, por consecuencia, un desarrollo anormal de los embriones. Para solucionar este obstáculo, en el caso de Dolly las células de tejido mamario donador del núcleo fueron cultivadas in vitro, en ausencia de suero, para detener el ciclo celular en G0. La transferencia de un núcleo de estas células al ovocito enucleado permitió la sincronización del núcleo donador y el citoplasma receptor, iniciando el desarrollo embrionario y minimizando la probabilidad de alteraciones cromosómicas (WILMUT et. al., Op. cit.).

La eficiencia en la producción de embriones clonados ha sido mejorada debido a la utilización de métodos de electrofusión en lugar del método tradicional de microinyección para la transferencia nuclear (HOSAKA et. al., Op.cit.). El uso de la transferencia de núcleos de células somáticas (del inglés SCNT - somatic cell nuclear transfer) ha permitido el desarrollo de interesantes experimentos en los últimos seis años, después de la exitosa clonación de Dolly con una célula adulta. Las técnicas de clonación descritas a la fecha han proporcionado avances importantes en el conocimiento de la interacción molecular y celular durante los procesos tempranos del desarrollo 
y de la diferenciación celular (MOLLARD, et. al., 2002). Sin embargo, el obvio progreso, y el gran impacto de estas nuevas biotecnologías, ha hecho también evidente lo poco que se conoce del mecanismo de "reprogramación molecular" que se presenta en la SCNT. Debido a lo anterior, se han desarrollado nuevos enfoques experimentales, con los que se está abordando el estudio de los diferentes tipos de células donadoras, de los estadios del ciclo celular, del proceso de sincronización celular, del tiempo de duplicación de las diferentes poblaciones celulares hasta del nacimiento del organismo clonado, y de la influencia de la SCNT en la viabilidad y la capacidad de reproducción de los clones producidos (BREM \& KUHHOLZER, 2002).

\section{Transmisión del Genoma Nuclear y Mitocondrial}

Las células eucarióticas contienen dos distintos genomas: el nuclear, heredado a la progenie siguiendo el modelo mendeliano; y el mitocondrial, transmitido mediante herencia materna. La clonación de mamíferos ha sido llevada a cabo, típicamente, mediante SCNT, usando electrofusión. En este proceso, la célula somática completa es transferida al ovocito enucleado. Por consecuencia, la progenie clonada debería contener, además del genoma nuclear, el genoma mitocondrial de los dos progenitores (heteroplasmia). La transferencia del genoma nuclear fue verificada utilizando marcadores somáticos específicos del ADN nuclear. Sin embargo, el análisis del origen del ADN mitocondrial de Dolly, y de más nueve ovejas clonadas de células fetales, mostró que el genoma mitocondrial de estos individuos clonados provenía única y exclusivamente de los ovocitos enucleados sin contribución de la células somáticas donadoras (EVANS et. al., 1999).

Con base en lo anterior, Dolly no fue una copia idéntica o clon de la madre donadora del núcleo. Realmente, constituyó una auténtica quimera genética, ya que contenía el genoma nuclear de la célula somática donadora y el genoma mitocondrial del ovocito receptor. Públicamente, fue considerada como el producto de tres "madres": la donadora del núcleo que proporcionó el material genético nuclear, la donadora del óvulo que contribuyó con el citoplasma y el material genético mitocondrial, y la gestadora que genéticamente no aportó nada. 


\section{Desarrollo y Envejecimiento Celular}

Ha sido una preocupación científica la cuestión de "edad genética" de los organismos clonados, ya que estos podrían envejecer prematuramente y, potencialmente, presentar problemas en el desarrollo normal del organismo. La presencia de telómeros $20 \%$ más cortos en Dolly, en comparación con el promedio de ovejas de su misma edad, ha sido investigada. Este aspecto es importante, ya que los telómeros se acortan en cada división celular, y han sido considerados como marcadores de envejecimiento. En un estudio realizado en 24 vacas clonadas, se observó la presencia de telómeros más largos que el promedio que presentan los individuos de su misma edad. Además, el análisis de terneros clonados de células fetales mostró la presencia de telómeros normales, dejando abierta la pregunta de si los telómeros cortos de Dolly son una excepción o un hecho general, que podría ser diferente en las clonas derivadas de fetos (TIAN et. al., 2000).

En el marco anterior, existe una controversia abierta sobre la posible ocurrencia de envejecimiento prematuro, ya que Dolly fue sacrificada debido al cáncer de pulmón de origen vírico diagnosticado a ella y a otras ovejas que convivían con ella. Asimismo, la presencia de artritis en la pata izquierda de Dolly ha puesto en duda la factibilidad de los organismos clonados para usos terapéuticos. Aunque la artritis es común en ovejas, ésta se presenta a una edad típica de 10 años, en lugar de 5,5 años como fue el caso de Dolly. Además, las articulaciones afectadas en ésta se encontraron en lugares dónde normalmente no se presenta la artritis; por lo que, muy probablemente, la enfermedad fue debida al desarrollo de inflamación en las patas.

Por otro lado, un estudio publicado acerca de las condiciones de salud de 335 individuos clonados, mostró que el 77\% de vacas, ovejas, cabras, cerdos y ratones no presentaron problemas de salud, porcentaje que es representativo de lo que sucede normalmente en las poblaciones de los mamíferos mencionados.

Adicionalmente, se tenían dudas sobre la fertilidad de Dolly, ya que ésta podría verse afectada en comparación con una oveja concebida en forma natural. La progenie de Dolly con seis corderos saludables muestra que, en este caso, la fertilidad no se vio afectada. 


\section{Clonación Humana}

La estrategia que permitió crear a Dolly puede ser usada para clonar cualquier especie de mamíferos, incluyendo al ser humano. A la fecha, se ha mostrado que tanto las células somáticas como las células del cúmulus, las células de Sertoli y los fibroblastos pueden ser usadas como donadoras de núcleos para la clonación en animales. Recientemente, los resultados del grupo de Cibelli mostraron que efectivamente se han podido obtener embriones humanos clonados mediante SCNT usando células de cúmulo. Sin embargo, éstos se dividieron solamente en dos, cuatro y seis células, es decir, en etapas tempranas del desarrollo (CIBELLI et. al., 2001). Los autores atribuyen esto a problemas técnicos, como se ha mostrado en otros mamíferos. Sin embargo no se pueden descartar, a la fecha, los problemas reales en la re-programación del núcleo de una célula diferenciada, o los factores múltiples como el estadio del ciclo celular, estructura de la cromatina, metilación del ADN etc.

\section{Clonación reproductiva y terapéutica}

La clonación de humanos podría tener implicaciones terapéuticas y beneficios sociales si se usase bajo condiciones estrictas y excepcionales. La clonación humana podría tener dos finalidades: la clonación reproductiva, con el fin de crear un clon para parejas con problemas de fertilidad; y la clonación terapéutica, para obtener células o tejidos con fines terapéuticos y/o para regeneración de tejidos.

La clonación reproductiva implica la producción de embriones mediante la disgregación de células del blastocisto o por la SCNT a un óvulo enucleado, seguido, en ambos casos, de la implantación en un útero que permita su desarrollo hasta el nacimiento. En lo que se refiere a la clonación reproductiva humana, mucha especulación ha tenido lugar, con una profusión enorme de publicaciones al respecto. Sin embargo, la posibilidad de lograr una clonación humana con fines reproductivos exitosa es prácticamente nula. La investigación en varias especies de mamíferos ha demostrado que hay una incidencia muy alta - mayor del 95\% - de aparición de problemas embrionarios y fetales, con las subsecuentes pérdidas durante del embarazo; así como de malformaciones y muerte en los recién nacidos.

No hay razón para suponer que el resultado sería diferente en seres humanos. Esto se debe, fundamentalmente, a que se desconocen los 
mecanismos moleculares de reprogramación de un núcleo adulto de modo que puedan recobrar la plasticidad, la virginidad y pureza originales, i.e., tener las mismas características funcionales de sus genes que cuando tuvo origen a partir de un cigoto. No obstante, se tiene la expectativa de lograr evitar las fallas técnicas y, eventualmente, garantizar un producto con características "normales". De ahí que hayan surgido circunstancias hipotéticas que justificarían la clonación reproductiva. Por ejemplo, cuando se ha perdido un hijo, o se tiene uno con algún defecto evitable en un clon, en parejas con esterilidad, o que han perdido la capacidad de reproducción; o cuando no es posible la reproducción, como ocurre con las parejas homosexuales. Estas situaciones, desde el punto de vista científico, quitarían solidez al rechazo a la clonación reproductiva. Pero, esto no sería suficiente para levantar el veto y permitir su práctica, ya que aún habría importantes objeciones éticas, legales y sociales.

De manera similar a la clonación reproductiva, la clonación con fines terapéuticos y de investigación implica generar un blastocisto humano vía transferencia nuclear de la célula somática. Sin embargo, la diferencia crucial es que el blastocisto clonado nunca se implanta en útero alguno para el desarrollo de un organismo completo. En vez de esto, las células troncales aisladas del blastocisto se utilizan para generar líneas de células troncales, para investigaciones posteriores y para usos clínicos. Este tipo de clonación es, más bien, una terapia reconstitutiva para recuperar el tejido, mediante la producción de células de un individuo que permita la reposición de tejidos, evitando el problema del rechazo inmunológico. En este procedimiento, se requiere la clonación del individuo y, en las primeras etapas embrionarias, la obtención de las células madre embrionarias (COLMAN \& KIND, 2000). Es decir, se tomaría el núcleo de una célula somática del paciente para su transplante a un ovocito enucleado de una donadora. Este huevo, clonado, se dejaría desarrollar hasta formar un embrión en etapa de blastocisto, del que finalmente se obtendrían las células embrionarias, como fuente celular para el tratamiento del paciente.

Las primeras líneas celulares embrionarias fueron obtenidas de ratón y, posteriormente, de pollo, hamster, cerdo, mono Rhesus y, recientemente, de embriones humanos producto de fertilización in vitro (THOMSON et. al., 1998). En este trabajo, los embriones humanos fueron cultivados hasta la etapa de blastocisto, de dónde se aislaron las células de la masa interna, permitiendo obtener cinco líneas celulares que crecieron indiferenciadas durante cinco meses. Sin embargo, dado que los estudios sobre la 
producción de líneas celulares son recientes, gran parte del conocimiento que se tiene viene de los trabajos realizados en ratones, y no se han caracterizado todos los componentes y factores requeridos en la diferenciación celular.

Es indudable que la clonación terapéutica presenta todavía limitaciones importantes, ya que aún no se ha determinado cómo se lleva a cabo la diferenciación específica de estas células para ser eficientemente usadas en la terapia reconstitutiva; y es necesario perfeccionar el procedimiento de la clonación en el humano para la obtención de las células madre embrionarias.

Otro de los recientes logros adicionales derivados de la clonación, que presenta perspectivas muy interesante y halagadoras, fue la obtención de células madre mediante partenogénesis en ratones, monos y humanos (CIBELLI et. al., Op.cit.; CIBELLI et al., 2002). Es decir, se logró iniciar el proceso de la formación de un embrión a partir de un huevo no fertilizado hasta la formación de la cavidad de blastocele. Los resultados obtenidos presentan implicaciones muy relevantes en la clonación de células somáticas, y ofrecen una alternativa muy interesante en la generación de células madre sin la necesidad de contribución paterna.

Además, Rideout y colaboradores realizaron la corrección de un defecto genético en ratones mutantes mediante la combinación del transplante nuclear con la terapia génica (RIDEOUT et. al, 2002). En este trabajo, se llevó a cabo el aislamiento de las células madre de los blastocistos clonados, y éstas se utilizaron para la reparación de la mutación mediante recombinación homóloga, así como en la diferenciación de la células madre y el transplante de las células en los ratones afectados. Estos logros revolucionarios presentan, sin lugar a dudas, un horizonte muy promisorio en el campo de la investigación de las células madre, así como en su aplicación terapéutica.

\section{Producción de Biofármacos}

El impacto de la clonación también ha sido evidente en la fabricación de productos biofarmacéuticos en el área biomédica. La generación de animales transgénicos para la producción y secreción, a través de la leche, de proteínas para usos terapéuticos, se inició a finales de los años 80 con la producción de ovejas transgénicas. La oveja Tracy produce la proteína humana alfa-1antitripsima, representando el 50\% de las proteínas de su leche. Hay muchos otros ejemplos de productos biofarmacéuticos utilizados para combatir 
enfermedades, como es el caso de la fibrosis quística, que se encuentra actualmente en fase clínica. Estas tecnologías presentan varias limitaciones. Por ejemplo, no se pueden dirigir las inserciones del ADN específicamente en el genoma del animal, la producción de los animales es lenta y los niveles de expresión de la proteína de interés son impredecibles. La tecnología de clonación presenta ventajas debido al desarrollo de la transferencia de núcleos somáticos, previamente manipulados genéticamente, en las células somáticas, principalmente cuando las manipulaciones son dirigidas a sitios predeterminados en el genoma hospedero. Este objetivo fue alcanzado con el nacimiento de Polly, una oveja clonada que expresa una proteína involucrada en la prevención de la hemofilia humana, codificada por el gen para el factor IX de la coagulación (COLMAN, Op. cit.).

\section{Consideraciones Éticas y Sociales}

La clonación en humanos es un tópico altamente controversial, debido a que la idea de crear una copia de un individuo mediante manipulación genética es simultáneamente fascinante y, de alguna forma, aterradora.

Existen aún problemas técnicos y científicos para el éxito de la clonación en humanos, ya que aún es muy prematuro determinar si los individuos clonados pueden poseer susceptibilidad a enfermedades, a un envejecimiento prematuro, entre otros problemas (PERRY \& WAKAYAMA, 2002). Los riesgos potenciales de la clonación, aunados a la baja eficiencia del proceso obtenido a la fecha, han llevado a la sociedad en general a sostener el posicionamiento de que no se justifica la clonación para generar individuos clonados, ya que la reproducción asistida actualmente resuelve los problemas de infertilidad mediante fertilización in vitro.

Por otro lado, la utilización de embriones humanos en experimentación y clonación terapéutica ha causado también mucha inquietud. El tema central de discusión es determinar el momento en que se puede considerar que se inicia la vida del individuo, ya sea inmediatamente después de la fertilización, a partir de la implantación del huevo fecundado; o hasta que el sistema nervioso se vuelve funcional. Lo anterior se debe, principalmente, a que la obtención de las líneas celulares madre implica la destrucción posterior del embrión clonado. Es evidente que el uso de embriones humanos para la obtención de líneas de células madre embrionarias abre nuevas perspectivas para el tratamiento de una gran cantidad de enfermedades. Sin embargo, su 
aplicación podría traspasar los límites éticos, a pesar de los beneficios que pueda representar.

La respuesta legislativa de diferentes países con relación a la clonación en humanos ha sido la de postular leyes para evitar cualquier investigación en la clonación en humanos. Algunos beneficios potenciales han sido resumidos en las leyes europeas y en la Convención Europea de los Derechos Humanos (WOOD, 1999). Sin embargo, la pregunta latente e inevitable es si estas restricciones legislativas serán suficientes para frenar la clonación en humanos, y si estamos preparados para afrontar el complejo dilema, tanto ético como moral, que se podría producir en la clonación reproductiva.

En lo que se refiere a la clonación terapéutica y con fines de investigación, la perspectiva es sin duda prometedora, ya que podremos mejorar nuestro conocimiento básico como, por ejemplo, en cuanto a: 1) reprogramar el núcleo de la célula para activar el sistema de genes que caracteriza a una determinada célula especializada; 2) entender las bases genéticas de las enfermedades humanas; 3) entender mejor los mecanismos de la reprogramación de genes y, por consiguiente, poder diseñar procedimientos eficientes para corregir genes defectuosos. Otra meta es aprender a reprogramar células somáticas para generar células madre que ocurren en todas las etapas del desarrollo, desde el embrión al adulto. Pero su versatilidad y abundancia disminuyen gradualmente con la edad.

Sin embargo, mientras las células madre embrionarias pueden producir cualquiera de los aproximadamente 200 diversos tipos de células especializadas que conforman el cuerpo humano, las células madre del adulto parecen ser capaces de producir solamente un número muy limitado de tipos celulares. La investigación usando huevos humanos es indispensable, ya que los estudios en animales no pueden proporcionar una alternativa apropiada para el objetivo perseguido. Estas técnicas ofrecen la posibilidad de usos terapéuticos para los pacientes que requieren transplantes de células, tejidos u órganos mediante células madre embrionarias genéticamente compatibles con el donante, evitando así el problema del rechazo. Sin embargo, aparte de los retos propiamente científicos, hay problemas con el costo de tratamientos que resuelvan las necesidades particulares de cada paciente, y del suministro de óvulos humanos no fertilizados. Actualmente, como la clonación es un proceso poco eficiente, es probable que sean necesarios muchos huevos para generar una sola línea embrionaria de células madre; y aún no hay la certeza de que la clonación con fines terapéuticos sea clínicamente viable. 
La intensa discusión mundial acerca da la clonación humana ha dado lugar a una multiplicidad de declaraciones, pronunciamientos etc., que van desde la anuencia total a la prohibición absoluta. Para una revisión general de tal tipo de pronunciamientos, basta con consultar los sitios en Internet: http://www.humgen.umontreal.ca/en/, http://www.un.org/law/cloning/, y http:/ /www4.nas.edu/iap/iaphome.nsf?opendatabase.

Las Academias de Ciencia de más de 70 países concluyeron que la clonación con fines terapéuticos y de investigación tiene un gran potencial desde la perspectiva científica y médica, por lo que se debe diferenciarla claramente de la clonación reproductiva y, por lo tanto, se debe excluirla explícitamente de la prohibición de esta última, recomendando que ambas políticas necesitan ser revisadas, periódicamente, a la luz de los progresos científicos y sociales.

No obstante, el día 8 de marzo del 2005, la Asamblea General de las Naciones Unidas aprobó el texto de la Declaración de las Naciones Unidas sobre Clonación de Seres Humanos por 84 votos a favor, 34 en contra y 37 abstenciones. El texto aprobado establece, en su punto b), que los Estados Miembros "habrán de prohibir todas las formas de clonación de seres humanos en la medida en que sean incompatibles con la dignidad humana y la protección de la vida humana". Esta última parte condiciona, de alguna manera, una permisibilidad de la clonación de seres humanos - al menos la terapéutica - si se ofreciesen beneficios compatibles con la protección de la vida humana. De cualquier manera, siendo una Declaración, y por lo tanto no obligatoria incluso para los estados que votaron a favor, y que estuvo lejos de una aprobación unánime, su implementación de manera global es cuestionable. A pesar de ello, esperemos que las Organización de las Naciones Unidas, que promueve la discusión mundial y los subsecuentes consensos, no sólo sea respetada sino fortalecida por todos sus países miembros. Solo así podremos lograr la armonía en la diversidad.

Como sea que se desarrolle la investigación de la clonación con fines terapéuticos, el problema de fondo radica fundamentalmente en la inequidad de acceso a los beneficios que promete, así como ocurre con la fertilización in vitro, que sólo es factible en algunos países, con acceso preferencial para aquellos que pueden solventar los altos costos requeridos. Los costos de cualquier tipo de clonación humana seguramente serán lo suficientemente onerosos y, en consecuencia, excluyentes de las mayorías pobres del planeta.

El ser humano tal vez no sea, por naturaleza, un "animal moral": se ha convertido como tal en el curso de la evolución. La moral sirve para regular 
las relaciones entre los seres humanos. Sería, desde luego, excelente que para esta regulación tuviéramos conocimientos con el grado de certeza del conocimiento matemático. Sería deseable que tuviéramos una teoría ética que permitiera hacer aseveraciones morales verificables y que nos diesen la certeza de qué debemos hacer. Pero, todo ello no es possible:"nothing is good nor bad; we make it so", dice Shakespeare. La falacia naturalista es prácticamente inevitable. Lo que sí es posible es no desprender el deber ser del ser, y tener claridad de que ello no es posible. Es importante estar conciente de que no hay postulados éticos absolutos; lo que se puede hacer es no tener miedo a cometer la falacia naturalista - o metafísica - y a postular un deber ser moral, anunciando claramente en qué corriente nos encontramos.

A propósito de falacias, tanto las formales - afirmación de lo consecuente, quaternio terminorum, las falacias disectiva "del jugador", expansiva y de enfoque - como las informales - ignoratio elenchi, petitio principi y los argumenta ad baculum, hominem, misericordiam, populum, verecundiam etc. -- son de uso y abuso cotidiano. Si reflexionamos con rigor acerca del aforismo de Korzybski lo cual habla que "el mapa no es el territorio y el nombre no es la cosa nombrada", tenemos que aceptar que todo es según el color del cristal con que se mira, como querría Campoamor, y que sólo el silencio evita caer en la falacia. La imposible perfección y su incesante búsqueda, y la imposible conjunción de la moral y la economía, mantendrán el debate inagotable.

\section{Consideraciones Finales: la clonación social}

Hoy vivimos un mundo de amplísima diversidad que, con el anhelo de la globalización total, pretende una extremista clonación social que incluya la aceptación de "guerras defensivas", "invasiones preventivas" y toda clase de horrores, en los que el destaca eminentemente el "paupericidio", producto de la explotación, de la discriminación y del acceso selectivo a la nueva medicina.

Evidentemente, la clonación social es mucho más antigua que la ofrecida por la nueva biotecnología. Las religiones; los sistemas políticos, económicos y sociales; y la perpetua inercia auto replicante con los utópicos disfraces de libertad, igualdad y fraternidad, han mantenido diversificada pero, en cierto modo, en rivalidad a la comunidad mundial. Si bien la humanidad no es imaginable sin ciertos principios universales de moral y convivencia, se está 
propiciando ahora la forma más peligrosa de homogenización, a la que pretende llevarnos la propaganda publicitaria mediante la masiva tecnología de la comunicación, en la intención de enseñarnos a vivir con lo inaceptable.

\section{Referências Bibliográficas}

BREM, G. \& KUHHOLZER, B. The recent history of somatic cloning in mammals. Cloning Stem Cells 4(1): 57-63, 2002.

CIBELLI, J. B; KIESSLING, A. A.; CUNIFF, K.; RICHARDS, C.; LANZA, R., P. \& WEST, M.D. Somatic cell nuclear transfer in humans: pronuclear and early embryonic development. The J. of Regenerative Medicine 2: 25-31, 2001.

CIBELLI, J.B.; GRANT, K. A.; CHAPMAN, K. B.; CUNNIFF, K.; WORST, T.; GREEN, H. L.; WALKER, S. J.; GUTIN, P. H, VILNER, L, TABAR, V.; DOMINKO, T.; KANE, J., WETTSTEIN, P.J.; LANZA, R. P.; STUDER, L.; VRANA, K. E. \& WEST, M. D. Partenogenetic stem cells in nonhuman primates. Science 1, 295 (5556): 819, 2002.

COLMAN, A. Dolly, Polly and other 4 ollys $\$$ : likely impact of cloning technology on biomedical uses of livestock. Genet Anal, 15 (3-5): 167-173, 1999.

COLMAN, A. \& KIND, A. Therapeutic cloning. Concepts and practicalities. Trends Biotechnol 18(5): 192-196, 2000.

EVANS, M. J.; GURER, C.; LOIKE, J. D.; WILMUT, I.; SCHINIEKE, A. E. \& SCHON, E. A. Mitochondrial DNA genotypes in nuclear transfer-drived cloned sheep. Nat Genet 23 (1): 90-93, 1999.

GURDON, J. B. The developmental capacity of nuclei taken from intestinal epithelium cells of feeding tadpoles. J. Embrión Exp. Morphol. 10: 622-640, 1962

GURDON, J. B.; LASKEY, R. A. \& REEVES, O. R. The developmental capacity of nuclei transplanted from keratinized skin cells of adult frogs. J. Embryol. Exp. Morph, 34: 93-112, 1975.

HOSAKA, K.; OHI, S.; ANDO, A.; KOBAYASHI, M. \& SATO, K. Cloned mice derived from somatic cell nuclei. Hum. Cell, 13(4): 237-242, 2000.

MAIAENSCHEIN, J. On cloning: advocating history of biology in the public interest. J. Hist. Biol, 34(3): 423-432, 2001.

McGRATH, J. \& SOLTHER, D. Inability of mouse blastomere nuclei transferred to enucleated zygotes to support development in vitro. Science, 226: 1317-1319, 1984.

MOLLARD, R., DENHAM, M.; TROUNSON, A. Technical advances and pitfalls on the way to human cloning. Differentation, 70(1): 1-9, 2002.

PERRY, A. C. \& WAKAYAMA, T. Ultimately ends and new begginings in mouse cloning. Nat. Genet, 30: 243- 244, 2002.

POLEJAEVA, I. A.; CHEN, S. H.; VAUGTH, T. D.; PAGE, R. L.; MULLINS, J.; BALL, S.; DAI, V.; BOONE, J.; WEALKER, S.; AYARES, D. L.; COLMAN, A. \& CAMPBELL, K. M. S. Cloned pigs produced by nuclear transfer from adult somatic cells. Nature, 407: 86-90, 2000. 
RIDEOUT, W. M.; HOCHEDLINGER, K.; KYBA, M.; DALEY, G. Q. \& JAENISCH, R. Correction of a genetic defect by nuclear transplantation and combined cell and gene therapy. Cell, 108: 645-656, 2002.

THOMSON, J. A.; ITSKOVITZ-ELDOR, J.; SHAPIRO, S. S.; WAKNITZ, M. A.; SWIERGIEL, J. J,; MARSHALL, V. S. \& JONES, J. M. Embryonic stem cell lines derived from human blastocists. Science, 282 (5391):1145-7, 1998.

TIAN, X. C.; XU, J. \& YANG, X. Normal telomere lengths found in cloned cattle. Nat Genet, 26(3): 272-273, 2000.

WILMUT, I.; SCHNIEKE, A. E.; McWHIR, J.; KIND, A. J. \& CAMPBELL, K. H. Viable offspring derived from fetal and adult mammalian cells. Nature, 385: 810813, 1997.

WOOD, P. G. To what extent can the law control human cloning?. Med. Sci. Law, 39 (1): 5-10, 1999.

\section{Recebido em 27/5/2005}

Aprovado em 18/8/2005 